\title{
State Level Poverty: The Case Of New York
}

Robert G. Mogull, (E-mail: mogullr@ csus.edu), California State University, Sacramento

\begin{abstract}
This study serves two purposes. First, it demonstrates a method of estimating and projecting annual poverty at sub-national levels. Data are obtained from decennial censuses and form the benchmarks from which poverty is estimated and projected for separate demographic groups. Projections are based upon historical curvilinear trends for each group. The methodology demonstrated can be easily applied in a variety of jurisdictional settings and levels. The second objective is to provide a portrait of poverty by demographic group specifically within the State of New York. The evidence indicates that New York can anticipate a substantial poverty increase over the next decade. There will also be major shifts among demographic groups in their shares of overall State poverty.
\end{abstract}

\section{INTRODUCTION \& BACKGROUND}

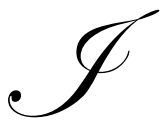

$\mathrm{n}$ a recent article, the author estimated and projected annual poverty by demographic group within a major metropolitan area. The purpose of that paper was two-fold. In addition to examining the specific poverty profile of the New York City PMSA (Mogull: 2005), the objective was also to demonstrate a method of creating annual poverty estimates at the sub-national level. Such data are not available from any official source.

As discussed in that article, the U.S. Census Bureau has provided two principal estimates of poverty since 1960 (for poverty since 1959), where both estimates have been widely used in academia, in commerce, by advocacy groups and by governments at all jurisdictional levels. The two resulting estimates, however, are often very different from each other.

One source of official poverty statistics has been the Current Population Surveys (CPS). These are conducted annually during the month of March and consist of supplemental questions to their basic monthly surveys of employment and unemployment (for the Bureau of Labor Statistics). The nationwide CPS reaches approximately 50,000 civilian non-institutional households. In year 2000, for example, 51,016 households were sampled throughout the United States, including 3,307 within the State of New York. However, in year 2000, there were over 105 million occupied households in the nation including over seven million in New York State. (The Census Bureau defines a household as consisting of either a single individual or a group of people who occupy a common housing unit, whether related or not.)

Annual CPS poverty data are reported separately for the nation, regions, a few large counties and an aggregation of the 10 largest metropolitan areas. Due to the small samples, poverty at state levels are reported only as 2 -year or 3-year moving averages. The national data are categorized by race and by Hispanic ethnicity, where Hispanics are also counted separately by race. These categories currently consist of: Asians, Blacks, Hispanics (of any race), Native Americans, Native Hawaiians \& Other Pacific Islanders, Non-Hispanic Whites, Some Other Race, Two or More Races and all Whites. Although poverty by demographic group is not reported for sub-national jurisdictions, even at the national level aggregate CPS statistics are highly erratic, unstable, volatile and unreliable.

The other primary source of official poverty statistics are the decennial censuses, where poverty has been measured by the Bureau also since 1960 (for poverty since 1959). Census data are obtained from all jurisdictional 
levels throughout the nation and U.S. Territories -- including states, counties, cities, towns, tracts and blocks. Data are collected and classified for many separate (but not necessarily mutually exclusive) demographic groups. Census statistics are compiled from much larger samples than the CPS, consisting over the years of between 15\% and 25\% of all civilian non-institutional housing units. In Census 2000, for example, the national poverty sample contained almost 17.6 million households, with more than one million in New York State.

The official definition of poverty was originally designed in 1964 by Mollie Orshansky of the Social Security Administration (Orshansky: Jan. 1965, July 1965, 1969). The definition and thresholds have provided a consistent measure of poverty since 1959 and, in 1969, were formally established for use by all federal agencies. Poverty indexes are based upon pre-tax earned money income only and currently vary according to the age of the family head and the number of family members. Before 1982, index cut-off levels also considered the gender of the household head and whether the family resided on a farm. Annual changes in living costs are factored into the national poverty thresholds using the Consumer Price Index for Urban dwellers. Weighted average poverty thresholds for a family of four, for example, have grown from \$2,973 in 1959 to \$19,484 in 2004.

\section{METHODOLOGY \& GOALS}

In this paper, estimates and projections of State annual poverty will be based upon the decennial census tabulations for two reasons. First; because of their far larger sample sizes, decennial census estimates of poverty are far more reliable and probably also more accurate. Second; the Current Population Surveys do not report annual poverty for demographic groups at sub-national levels. Only the decennial censuses compile state poverty data by demographic group (but only at 10-year intervals).

Decennial census statistics provide the discrete benchmarks that will be used to compute continuous smoothed trends in poverty for separate (but non-mutually exclusive) demographic groups within the State of New York. The universe of benchmark years consists of 1959, 1969, 1979, 1989 and 1999. Tables 1 and 2 list the officially tabulated poverty rates and counts of poverty persons, respectively, for those years. These decennial statistics will be the anchors for independently computed trend lines.

Smoothed trend lines will be created by quadratic curvilinear regressions using statistics for the years 1979 , 1989 and 1999 only (from the decennial censuses of 1980,1990 and 2000) and extrapolated a decade to year 2009 (when a new set of poverty benchmarks will be established by the census of 2010). The data fit of each respective polynomial regression line is intentionally designed to be "perfect" and each parabolic trend line will intersect all three plotted points for a demographic group.

The resulting trend lines will contain several assumptions. For example; they will assume that intervening years of poverty are accurately portrayed by smoothed temporal estimates. The projections will further assume that the bases for the historical curvilinear trends will continue - such as in rates of fertility, mortality and immigration. In addition; it will be presumed that there will be no major disruptions in the trends due to wars, epidemics, natural disasters (such as an earthquake or flood) or other special events. The independent variable "Year" serves as a collective proxy for a wide variety of economic, social, psychological and chance factors that can affect poverty over time.

It should again be emphasized that annual poverty rates and counts by demographic group are not estimated by any official source for sub-national jurisdictions. Although the CPS does provide annual poverty estimates for states, they are reported for all demographic segments combined. These estimates often are disaggregated by the states, however, despite the caution stated by the Census Bureau. But, by breaking down the overall aggregate statistics, the already low reliability of CPS poverty figures is magnified.

Neither the CPS nor the decennial census estimates of poverty make adjustments for regional living costs. And, since the cost of living for most residents of New York State exceeds the national average (Bureau of the Census: 2002), official poverty measures systematically underestimate poverty for the State. If such regional differentials were accounted for, both the rates and the numerical counts of State impoverishment would shift up. Yet, 
the upward shifts would not be uniform, as it is likely that some demographic groups would be affected more than others.

Table 1: Decennial Census Poverty Rates New York State

\begin{tabular}{|c|c|c|c|c|c|}
\hline Group & $\mathbf{1 9 5 9}$ & $\mathbf{1 9 6 9}$ & $\mathbf{1 9 7 9}$ & $\mathbf{1 9 8 9}$ & $\mathbf{1 9 9 9}$ \\
\hline All Persons & 14.2 & 11.1 & 13.4 & 13.0 & 14.6 \\
Asians \& Pacific Islanders & $\mathrm{n} / \mathrm{a}$ & $\mathrm{n} / \mathrm{a}$ & 13.3 & 14.5 & 17.5 \\
Blacks & $\mathrm{n} / \mathrm{a}$ & 23.9 & 28.3 & 25.0 & 25.0 \\
Children (related, under age 18) & $\mathrm{n} / \mathrm{a}$ & 12.7 & 19.0 & 18.8 & 19.6 \\
Elderly (age 65 and over) & 28.2 & 20.7 & 11.6 & 11.9 & 11.3 \\
Female Family Heads & 29.4 & 28.1 & 34.2 & 30.1 & 29.2 \\
Hispanics (of any race) & $\mathrm{n} / \mathrm{a}$ & $\mathrm{n} / \mathrm{a}$ & 33.1 & 30.5 & 28.0 \\
Native Americans & $\mathrm{n} / \mathrm{a}$ & $\mathrm{n} / \mathrm{a}$ & 24.6 & 23.5 & 27.3 \\
Non-Hispanic Whites & $\mathrm{n} / \mathrm{a}$ & $\mathrm{n} / \mathrm{a}$ & 8.3 & 7.8 & 8.5 \\
Some Other Race & $\mathrm{n} / \mathrm{a}$ & $\mathrm{n} / \mathrm{a}$ & $\mathrm{n} / \mathrm{a}$ & 35.9 & 30.7 \\
Two or More Races & $\mathrm{n} / \mathrm{a}$ & $\mathrm{n} / \mathrm{a}$ & $\mathrm{n} / \mathrm{a}$ & $\mathrm{n} / \mathrm{a}$ & 23.8 \\
Whites & 12.4 & 9.3 & 9.4 & 8.7 & 9.8 \\
\hline
\end{tabular}

The specific goals of this paper are both to fill in for non-existent official demographic poverty data and to make projections for the next decade. The method demonstrated may be easily applied in other jurisdictional levels and settings. Consequently, this paper has two goals - first, to illustrate a convenient technique to estimate and project annual poverty at the sub-national level and, second, to focus on the unique demographics of the State of New York.

Table 2: Decennial Census Poverty Persons New York State

\begin{tabular}{|c|c|c|c|c|c|}
\hline Group & $\mathbf{1 9 5 9}$ & $\mathbf{1 9 6 9}$ & $\mathbf{1 9 7 9}$ & $\mathbf{1 9 8 9}$ & $\mathbf{1 9 9 9}$ \\
\hline All Persons & $2,319,301$ & $1,985,954$ & $2,298,922$ & $2,277,296$ & $2,692,202$ \\
Asians \& Pacific Islanders & $\mathrm{n} / \mathrm{a}$ & $\mathrm{n} / \mathrm{a}$ & 43,412 & 97,718 & 180,168 \\
Blacks & $\mathrm{n} / \mathrm{a}$ & 503,850 & 662,779 & 685,113 & 712,590 \\
Children (related, under age 18) & $\mathrm{n} / \mathrm{a}$ & 734,539 & 876,928 & 782,530 & 893,505 \\
Elderly (age 65 and over) & 468,499 & 405,932 & 235,830 & 265,863 & 264,336 \\
Female Family Heads & 131,470 & 166,534 & 273,416 & 271,681 & 294,906 \\
Hispanics (of any race) & $\mathrm{n} / \mathrm{a}$ & $\mathrm{n} / \mathrm{a}$ & 540,909 & 638,530 & 782,316 \\
Native Americans & $\mathrm{n} / \mathrm{a}$ & $\mathrm{n} / \mathrm{a}$ & 10,542 & 13,404 & 21,050 \\
Non-Hispanic Whites & $\mathrm{n} / \mathrm{a}$ & $\mathrm{n} / \mathrm{a}$ & $1,069,917$ & 948,147 & 970,780 \\
Some Other Race & $\mathrm{n} / \mathrm{a}$ & $\mathrm{n} / \mathrm{a}$ & $\mathrm{n} / \mathrm{a}$ & 344,190 & 404,158 \\
Two or More Races & $\mathrm{n} / \mathrm{a}$ & $\mathrm{n} / \mathrm{a}$ & $\mathrm{n} / \mathrm{a}$ & $\mathrm{n} / \mathrm{a}$ & 143,647 \\
Whites & $1,859,419$ & $1,448,772$ & $1,284,523$ & $1,136,871$ & $1,230,589$ \\
\hline
\end{tabular}

\section{THE EVIDENCE}

\section{The Past}

Figures 1 and 2 present plots of the universe of decennial census poverty for New York State for each demographic group (whose statistics are reported in Tables 1 and 2). The data points are connected by lines in order to facilitate a visual comparison of levels, directions, speeds and trends among the various groups. (The connecting lines are not created by regressions.) 


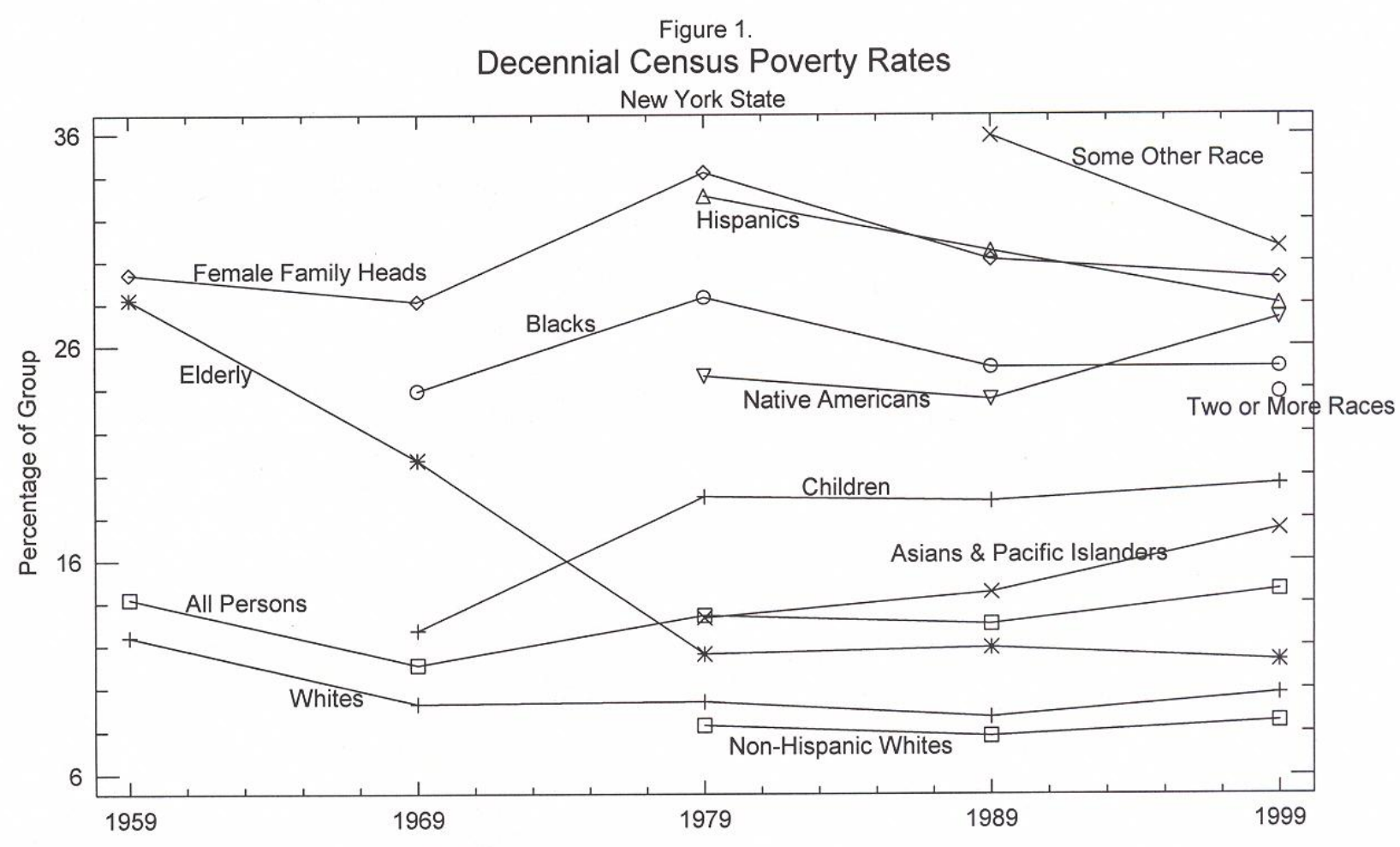

Source: Bureau of the Census, U.S. Department of Commerce.

From an examination of the poverty rates in Table 1/Figure 1 it is apparent that:

- Among All Persons, although the poverty rate changed directions each decade, the overall rate rose a very moderate $2.8 \%$ over the past 40 years. The rate was lowest in 1969 at $11.1 \%$ and highest in 1999 at $14.6 \%$. During the most recent past decade, the rate increased over $12 \%$ from $13.0 \%$ to $14.6 \%$.

- Asians \& Pacific Islanders saw their poverty incidence rise continuously and steeply by $32 \%$ from $13.3 \%$ in 1979 to $17.5 \%$ in 1999 . The change has accelerated and was much higher during the most recent decade (21\%) than the previous decade $(9 \%)$.

- Black poverty rates typically are among the highest of all demographic groups. Although their poverty incidence rose a sharp $18 \%$, from $23.9 \%$ in 1969 to $28.3 \%$ in 1979 , it subsequently declined $12 \%$ to a plateau of $25 \%$ in both 1989 and 1999.

- The rate of poverty among Children rose an especially steep 50\% between 1969 and 1979 from 12.7\% to $19.0 \%$. Since 1979, it has generally leveled off at that high level.

- Poverty rates for the Elderly declined by $27 \%$ during the 1960 s and by another $44 \%$ during the 1970 s in falling from $28.2 \%$ to $11.6 \%$. Rates have remained between $11 \%$ and $12 \%$ since 1979 . Over the past four decades, there has been a precipitous $60 \%$ drop from $28.2 \%$ to $11.3 \%$.

- The incidence of poverty among Female Family Heads has consistently exceeded those of most other demographic groups. Over four decades, there has been a modest $0.7 \%$ fall in rates from $29.4 \%$ in 1959 to $29.2 \%$ in 1999 . The decade of the 1970 s saw a particularly strong $22 \%$ rate of increase from $28.1 \%$ to $34.2 \%$. The slopes of trend lines for Children and for FFH during the 1970s were very similar and suggest a close linkage between the two groups.

- Hispanic rates declined 15\% between 1979 and 1999 from 33.1\% to $28.0 \%$. The decline was roughly the same in each decade at about $8 \%$. Nevertheless, the incidence of Hispanic poverty remains exceptionally high compared to other demographic groups, exceeding even Blacks. 
- After decreasing by $4.5 \%$ between 1979 and 1989, the poverty rate among Native Americans then rose more than $16 \%$ the following decade. Over the 20 -year period of measurement, there was an $11 \%$ growth from $24.6 \%$ in 1979 to $27.3 \%$ in 1999 .

- The poverty incidence among Non-Hispanic Whites is the lowest of all measured demographic groups. After falling 6\% between 1979 and 1989 from $8.3 \%$ to $7.8 \%$, rates rose $9 \%$ the following decade to $8.5 \%$.

- The Some Other Race population has experienced poverty rates above all other demographic groups. Between 1989 and 1999 , however, it declined almost $15 \%$ from $35.9 \%$ to $30.7 \%$.

- With just one year's measurement, the Two or More Races population segment had a relatively high poverty rate of $23.8 \%$ in 1999.

- White rates have typically been the lowest among all measured demographic groups (with the exception of NonHispanic Whites). Over four decades of measurement, their rates fell $21 \%$ from $12.4 \%$ in 1959 to $9.8 \%$ in 1999. The largest decline occurred during the 1960 s, when poverty dropped by $25 \%$ from $12.4 \%$ to $9.3 \%$. Since 1969 , the incidence has generally leveled off but, during the latest decade, rates rose $13 \%$ from $8.7 \%$ to $9.8 \%$.

Figure 2.

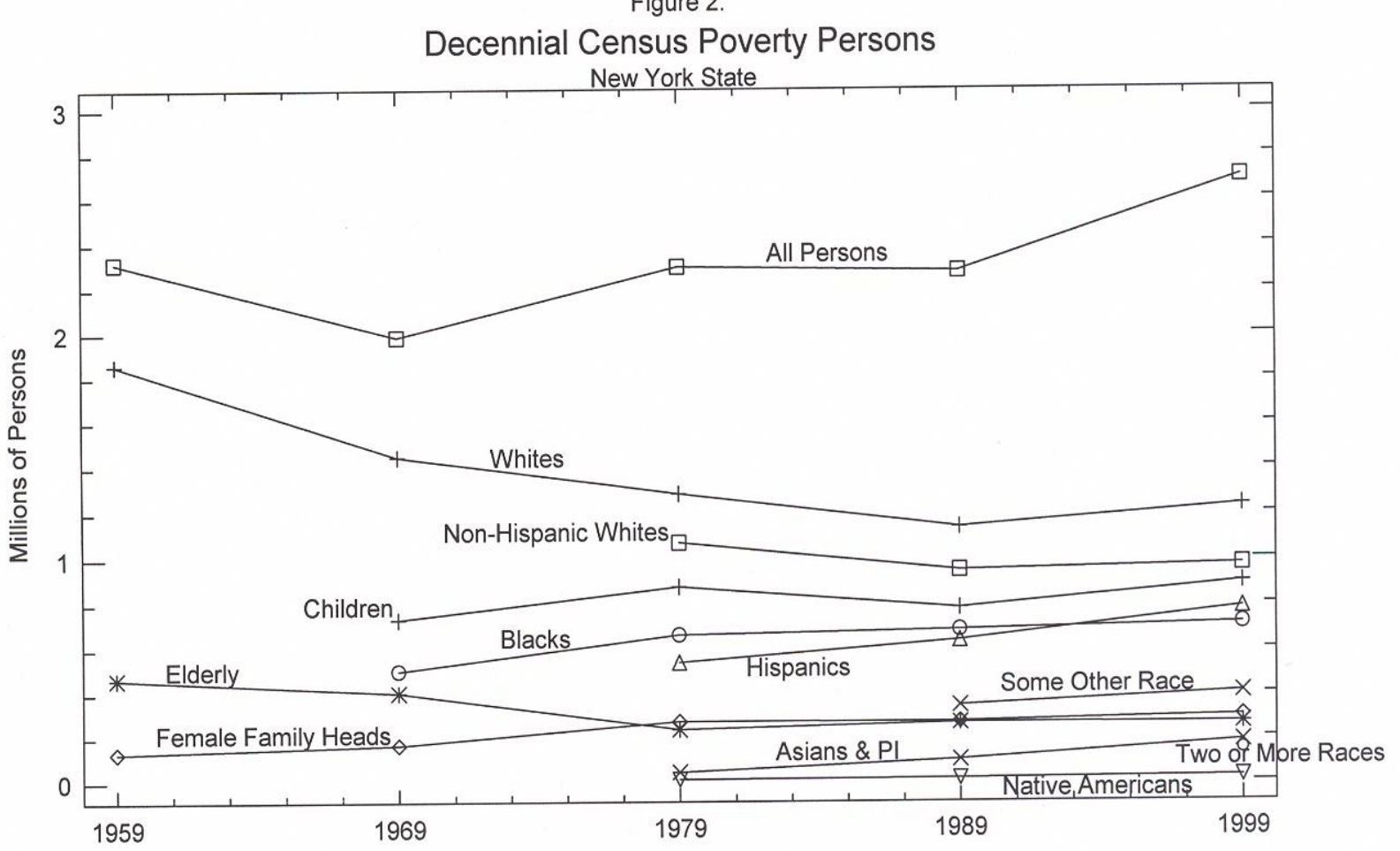

Source: Bureau of the Census, U.S. Department of Commerce.

Figure 2 plots the number of impoverished residents by demographic group for the universe of decennial census poverty measurements. These numbers can fluctuate over time due to changes in internal poverty rates and/or to changes in the number of residents affiliated with that group. Table 2/Figure 2 contributes to a more complete picture of historical State poverty. The evidence shows that:

- Over the past 40 years, the total number of persons below poverty thresholds rose $16 \%$ or by an annual average of $0.4 \%$. In 1959, there were 2.3 million poor persons in the State and, by 1999, there were 2.7 million. The decades of growth were the 1970s and the 1990s. During the most recent decade, poverty increased by $18.2 \%$.

- Asian \& Pacific Islander poverty shot up 315\% in just two decades or by an annual average of almost $16 \%$. In the 1980s, the number poor leapt 125\% from 43 thousand to 98 thousand. During the 1990s, it jumped another $84 \%$ to 180 thousand. As a consequence, whereas A\&PIs represented 2\% of the State total poor in 1979, they 
accounted for almost $7 \%$ in 1999. (In the most recent census, Asians alone accounted for $99.2 \%$ of the population of this joint group and $98.9 \%$ of the combined poverty.)

- Black poor over the 30-year interval increased from 504 thousand persons to 713 thousand for an increase of $41 \%$ or annual average growth of $1.4 \%$. Their share of overall State poverty has fluctuated between $25 \%$ and $30 \%$ and currently stands at almost $27 \%$.

- Over three decades, the number of Children in poverty rose $22 \%$ or by an annual average of $0.7 \%$ from 735 thousand in 1969 to 894 thousand in 1999. The decades of growth were the 1970s and the 1990s. However, their share of the State total poor has fallen from $37 \%$ to $33 \%$.

- Elderly poor shrank 44\% from 468 thousand in 1959 to 264 thousand in 1999 and their share of the State total fell by more than half from over $20 \%$ to less than $10 \%$. The 1970 s was the decade of greatest decline, when their numbers dropped by $42 \%$ from 406 thousand to 236 thousand. Although Elderly poverty rose $13 \%$ in the 1980s, it has since leveled off at around 264 thousand.

- Female Family Heads have seen a 124\% expansion over four decades or by an annual average of 3\% from 131 thousand in 1959 to 295 thousand in 1999. The 1970s was the period of greatest increase at $64 \%$. Their share of overall State poverty over the 40 years has jumped from $5.7 \%$ to $11 \%$.

- Hispanic poor grew $45 \%$ over 20 years or by an annual average above $2 \%$ from 541 thousand in 1979 to 782 thousand in 1999 . The $23 \%$ rate of increase during the 1990 s exceeded the $18 \%$ increase during the 1980 s and their share of State total poverty has risen from $24 \%$ to $29 \%$.

- Native American impoverishment rose $100 \%$ over just 20 years or by a $5 \%$ annual average from 10.5 thousand in 1979 to 21.1 thousand in 1999. As a share of overall State poverty, they have grown from $0.5 \%$ in 1979 to $0.8 \%$ in 1999.

- Non-Hispanic White poverty numbers declined 9\% over two decades or by $0.5 \%$ per year from 1.1 million in 1979 to under 1 million in 1999. In 1979, they accounted for $47 \%$ of the total State poor and by 1999 their share was "only" $36 \%$.

- The Some Other Race category rose 17\% during the decade of the 1990s from 344 thousand to 404 thousand and represented about 15\% of overall State poor in both 1989 and 1999.

- Two or More Races had just one year of measurement and accounted for about 144 thousand persons or 5.3\% of the total State poor in 1999.

- Between 1959 and 1999, White poor persons declined 34\% from 1.9 million to 1.2 million or by an annual average of $0.8 \%$. The 1960s saw the greatest drop at 22\%. During the recent 1990s, however, there was an $8.2 \%$ increase. In 1959, Whites accounted for over $80 \%$ of overall State poverty, but that share has receded continuously to less than $46 \%$ in 1999 .

\section{The Present}

Before looking to the future, let us examine the most current decennial census snapshot of poverty within New York State. Figure 3 provides a cross-sectional illustration of poverty rates among the various demographic groups. Across all groups, the overall incidence in 1999 is $14.6 \%$. In descending order, those segments with the highest rates are: Some Other Race (30.7\%), Female Family Heads (29.2\%), Hispanics (28.0\%), Native Americans (27.3\%), Blacks (25.0\%), Two or More Races (23.8\%), Children (19.6\%), Asians \& Pacific Islanders (17.5\%), the Elderly (11.3\%), Whites in general (9.8\%) and Non-Hispanic Whites (8.5\%). 
Figure 3.

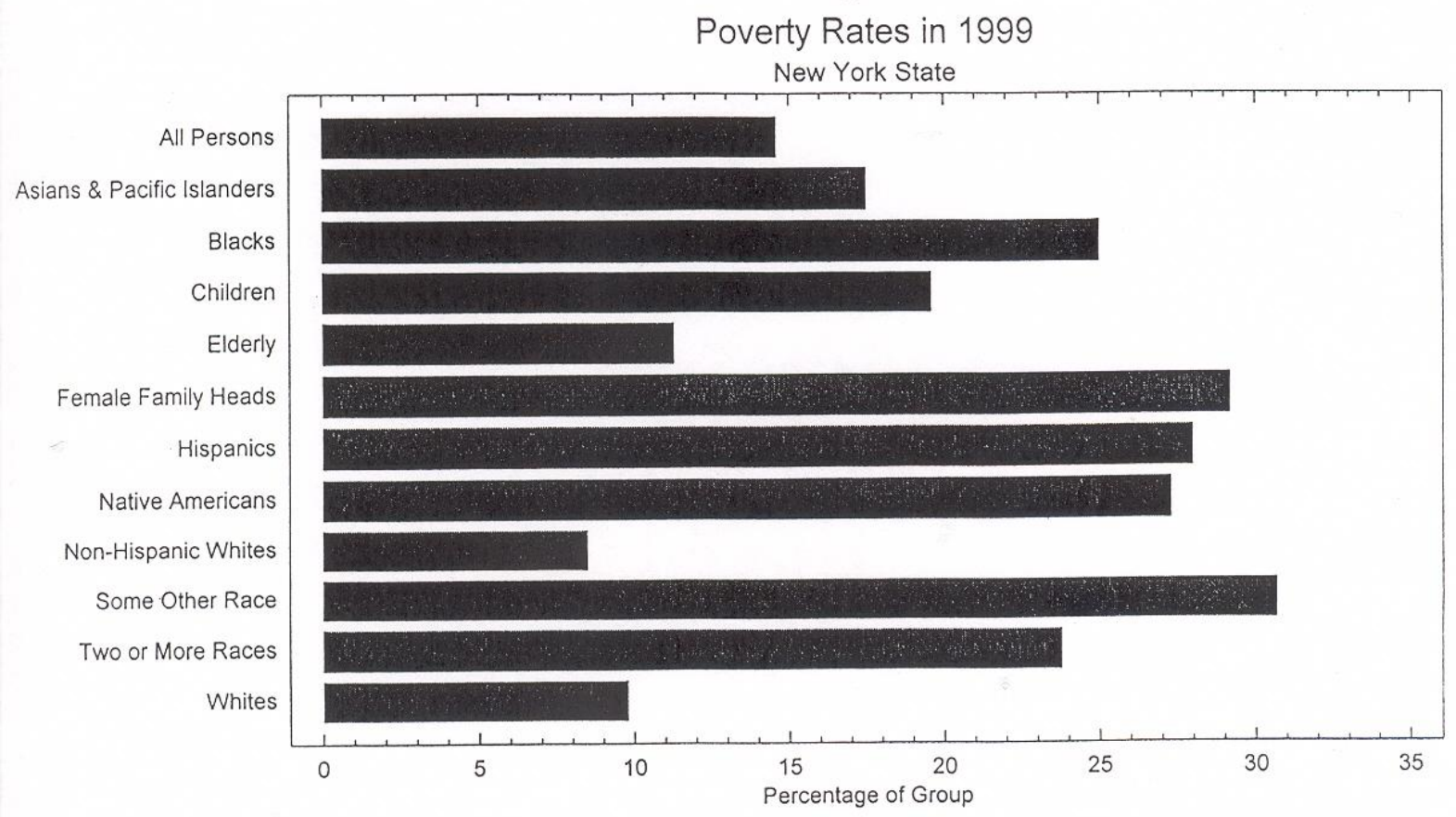

Source: Bureau of the Census, U.S. Dept. of Commerce.

Table 3 reports and Figure 4 illustrates each demographic group's shares of State total poverty and total population. For example; although Whites represent $67.9 \%$ of the overall population, they account for "only" $45.7 \%$ of all poverty persons. Table 3 further presents the ratio of each group's share of total poverty to share of total population. The purpose of the far right-hand column is to indicate whether a particular group accounts for its "fair" share of overall poverty - where a value of one indicates an "appropriate" share, a ratio greater than one is an "excessive" share and a ratio of less than one is an under-representative share.

Table 3: Poverty \& Population Shares New York State

\begin{tabular}{|c|c|c|c|c|c|}
\hline \multirow[b]{2}{*}{ Group } & \multicolumn{2}{|c|}{1999 Poverty } & \multicolumn{2}{|c|}{2000 Population } & \multirow[b]{2}{*}{$\begin{array}{c}\text { Poverty \%/ } \\
\text { Population \% }\end{array}$} \\
\hline & Persons & Percent of Total & Persons & $\begin{array}{c}\text { Percent of } \\
\text { Total }\end{array}$ & \\
\hline All Persons & $2,692,202$ & 100.0 & $18,976,457$ & 100.0 & 1.0 \\
\hline Asians \& Pacific Islanders & 180,168 & 6.7 & $1,053,794$ & 5.6 & 1.2 \\
\hline Blacks & 712,590 & 26.5 & $3,014,385$ & 15.9 & 1.7 \\
\hline Children & 893,505 & 33.2 & $4,555,885$ & 24.0 & 1.4 \\
\hline Elderly & 264,336 & 9.8 & $2,448,352$ & 12.9 & .76 \\
\hline Female Family Heads & 294,906 & 11.0 & $1,038,176$ & 5.5 & 2.0 \\
\hline Hispanics & 782,316 & 29.1 & $2,867,583$ & 15.1 & 1.9 \\
\hline Native Americans & 21,050 & .78 & 82,461 & .43 & 1.8 \\
\hline Non-Hispanic Whites & 970,780 & 36.1 & $11,760,981$ & 62.0 & .58 \\
\hline Some Other Race & 404,158 & 15.0 & $1,341,946$ & 7.1 & 2.1 \\
\hline Two or More Races & 143,647 & 5.3 & 590,182 & 3.1 & 1.7 \\
\hline Whites & $1,230,589$ & 45.7 & $12,893,689$ & 67.9 & .67 \\
\hline
\end{tabular}




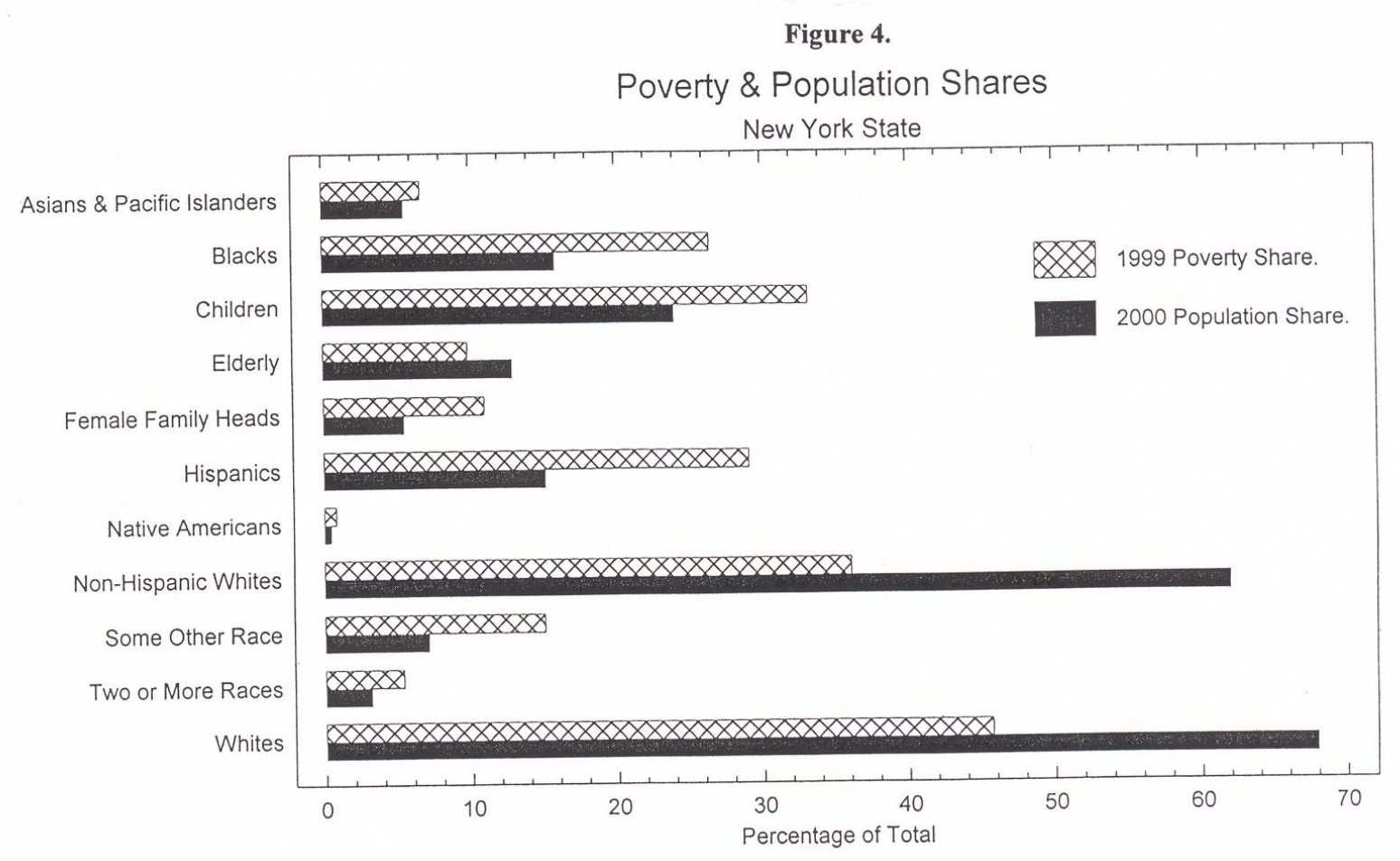

Source: Bureau of the Census, U.S. Dept. of Commerce.

As illustrated in Figure 4, in descending order, those demographic groups which account for excessive shares of total State poverty are: Some Other Race (with a ratio of 2.1), Female Family Heads (2.0), Hispanics (1.9), Native Americans (1.8), Two or More Races (1.7), Blacks (1.7), Children (1.4) and Asians \& Pacific Islanders (1.2). Those demographic groups with under-representative shares are: the Elderly (.76), Whites in general (.67) and NonHispanic Whites (.58).

\section{The Future}

The future is presumed to be a reflection of the past. Projected poverty trends in both rates and counts assume a continuation of patterns that have been previously established. These historical patterns are derived from the most recent three decennial census years of poverty measurement (1979, 1989 and 1999). Table 4 presents the computed polynomial regression coefficients for each separate demographic group.

To demonstrate how the specific regression equations yield annual estimates, we can look at examples for All Persons. Projections of the rate and the number of total impoverished state residents for year 2009 are:

- $\quad$ Poverty Rate $=39,454.9-39.72(2009)+0.01(2009)^{2}=18.2$

- $\quad$ Poverty Number $=8,598,030,000-8,662,960(2009)+2,182.66(2009)^{2}=3,535,915$ 
Table 4: Polynomial Regression Coefficients New York State

\begin{tabular}{|c|c|c|c|}
\hline \multirow{2}{*}{ Group } & \multirow{2}{*}{ Intercept } & \multicolumn{2}{|c|}{ Coefficient } \\
\hline & & First Degree & Second Degree \\
\hline \multicolumn{4}{|c|}{ Poverty Rates } \\
\hline All Persons & 39454.9 & -39.72 & 0.01 \\
\hline Asians \& Pacific Islanders & 35201.9 & -35.592 & 0.009 \\
\hline Blacks & 65629.2 & -65.802 & 0.0165 \\
\hline Children & 19739.7 & -19.86 & 0.005 \\
\hline Elderly & -17760.8 & 17.886 & -0.0045 \\
\hline Female Family Heads & 63825.3 & -63.898 & 0.016 \\
\hline Hispanics & 2515.76 & -2.244 & 0.0005 \\
\hline Native Americans & 96679.9 & -97.326 & 0.0245 \\
\hline Non-Hispanic Whites & 23724.6 & -23.858 & 0.006 \\
\hline Some Other Race & 1070.18 & -0.52 & ---- \\
\hline Whites & 35574.0 & -35.782 & 0.009 \\
\hline \multicolumn{4}{|c|}{ Poverty Persons } \\
\hline All Persons & $8.59803 \mathrm{E} 9$ & $-8.66296 \mathrm{E} 6$ & 2182.66 \\
\hline Asians \& Pacific Islanders & $5.43203 \mathrm{E} 8$ & -552946.0 & 140.72 \\
\hline Blacks & $9.74631 \mathrm{E} 7$ & -99803.7 & 25.715 \\
\hline Children & $4.06154 \mathrm{E} 9$ & $-4.08404 \mathrm{E} 6$ & 1026.86 \\
\hline Elderly & $-6.26845 \mathrm{E} 8$ & 629154.0 & -157.8 \\
\hline Female Family Heads & $4.91858 \mathrm{E} 8$ & -495380.0 & 124.8 \\
\hline Hispanics & $8.89802 \mathrm{E} 8$ & -906151.0 & 230.825 \\
\hline Native Americans & $9.35988 \mathrm{E} 7$ & -94628.4 & 23.92 \\
\hline Non-Hispanic Whites & $2.86719 \mathrm{E} 9$ & $-2.87713 \mathrm{E} 6$ & 722.015 \\
\hline Some Other Race & $-1.15834 \mathrm{E} 7$ & 5996.8 & ---- \\
\hline Whites & $4.78095 \mathrm{E} 9$ & $-4.80355 \mathrm{E} 6$ & 1206.85 \\
\hline
\end{tabular}

Smoothed trends with annual estimates are created for the time span 1979 through 2009 and are plotted in Figure 5 for rates and Figure 6 for persons.

From Figure 5, the independent demographic projections of rates of poverty indicate some significant temporal changes. Between 1999 and 2009: the overall rate of poverty for the State of New York is projected to grow 25\% from $14.6 \%$ in 1999 to $18.2 \%$ in 2009; the rate for Asians \& Pacific Islanders is forecast to rise $27 \%$ from $17.5 \%$ to $22.3 \%$; the Black rate will grow $13 \%$ from $25.0 \%$ to $28.3 \%$; the rate for Children will increase $9 \%$ from $19.6 \%$ to 21.4\%; the Elderly rate will decline $13 \%$ from $11.3 \%$ to 9.8\%; the rate for Female Family Heads will increase $8 \%$ from $29.2 \%$ to $31.5 \%$; the Hispanic rate will fall $9 \%$ from $28.0 \%$ to $25.6 \%$; the Native American rate will rise $32 \%$ from $27.3 \%$ to $36.0 \%$; the Non-Hispanic White rate will increase $22 \%$ from $8.5 \%$ to $10.4 \%$; the rate for Some Other Race will decline $17 \%$ from $30.7 \%$ to $25.5 \%$; and the White poverty rate is seen to rise $30 \%$ from $9.8 \%$ to $12.7 \%$. 


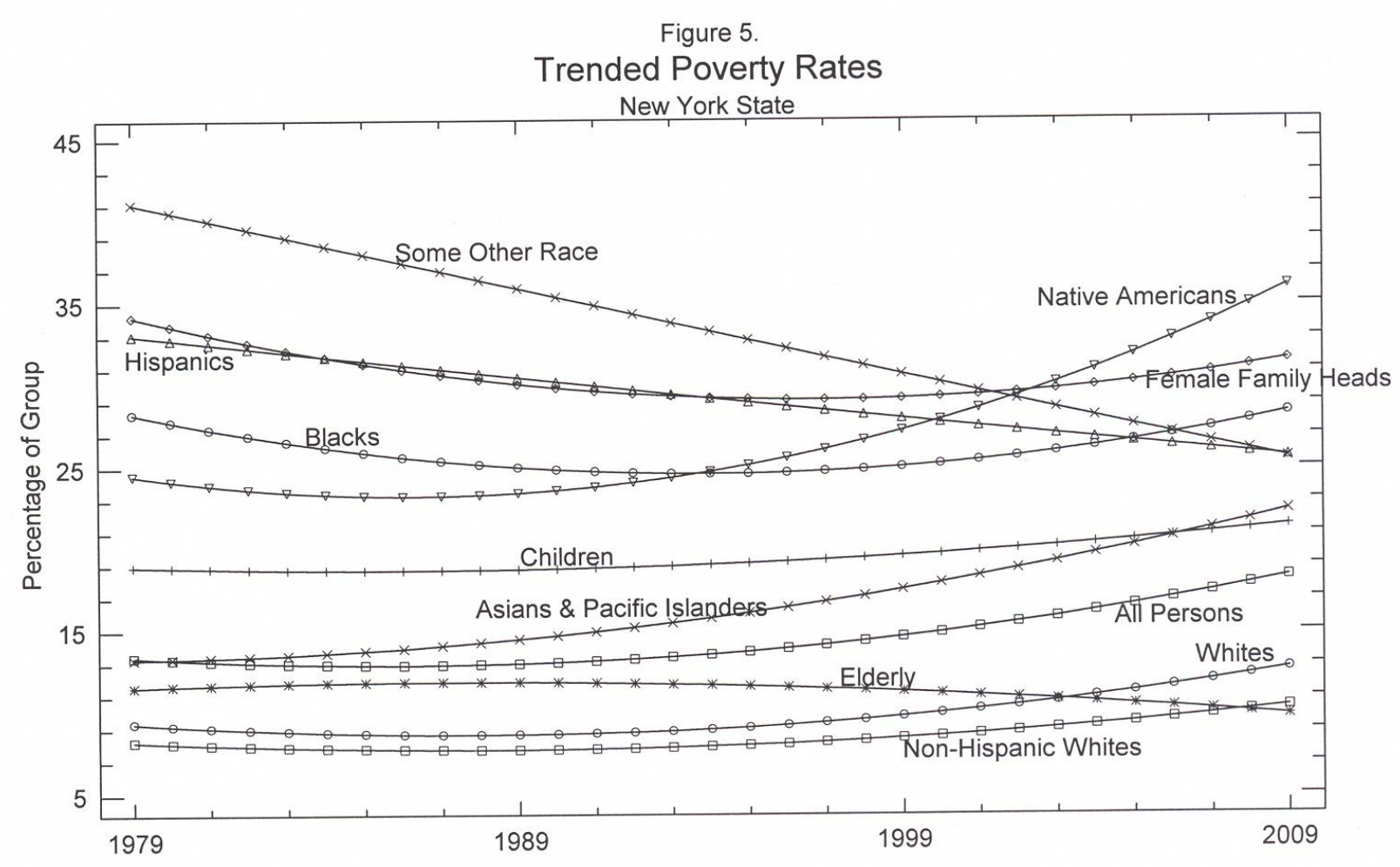

Figure 6 illustrates the independent demographic projections of counts of poor persons. Between 1999 and 2009: the total number of impoverished State residents is predicted to increase $31 \%$ from 2.7 million to 3.5 million; Asian \& Pacific Islander poor will jump 62\% from 180 thousand to 292 thousand and their share of the total State poor will rise from $6.7 \%$ to $8 \%$; Black poor will increase 5\% from 713 thousand to 745 thousand and their share of the total will decrease from $26.5 \%$ to $21 \%$; impoverished Children will increase $34 \%$ from 894 thousand persons to 1.2 million and their share will remain at around one-third; Elderly poor will decline 12\% from 264 thousand to 232 thousand and their share will fall from 9.8\% to 7\%; Female Family Heads will grow 16\% from 295 thousand to 342 thousand but their share will decrease from $11 \%$ to $10 \%$; Hispanic poverty persons will rise $24 \%$ from 782 thousand to 973 thousand yet their share will fall from $29.1 \%$ to $28 \%$; Native American poor will jump $59 \%$ from 21 thousand to 33 thousand and their share of overall State poverty persons will rise from $0.8 \%$ to $0.9 \%$; Non-Hispanic White poor will grow 18\% from 971 thousand to 1.1 million and their share will decrease from $36.1 \%$ to $32 \%$; Some Other Race will increase 15\% from 404 thousand to 464 thousand and their share will decline from $15 \%$ to $13 \%$; White poor will rise $27 \%$ from 1.2 million to 1.6 million and their share of overall State poverty is forecast to fall from $45.7 \%$ to about $44 \%$. 


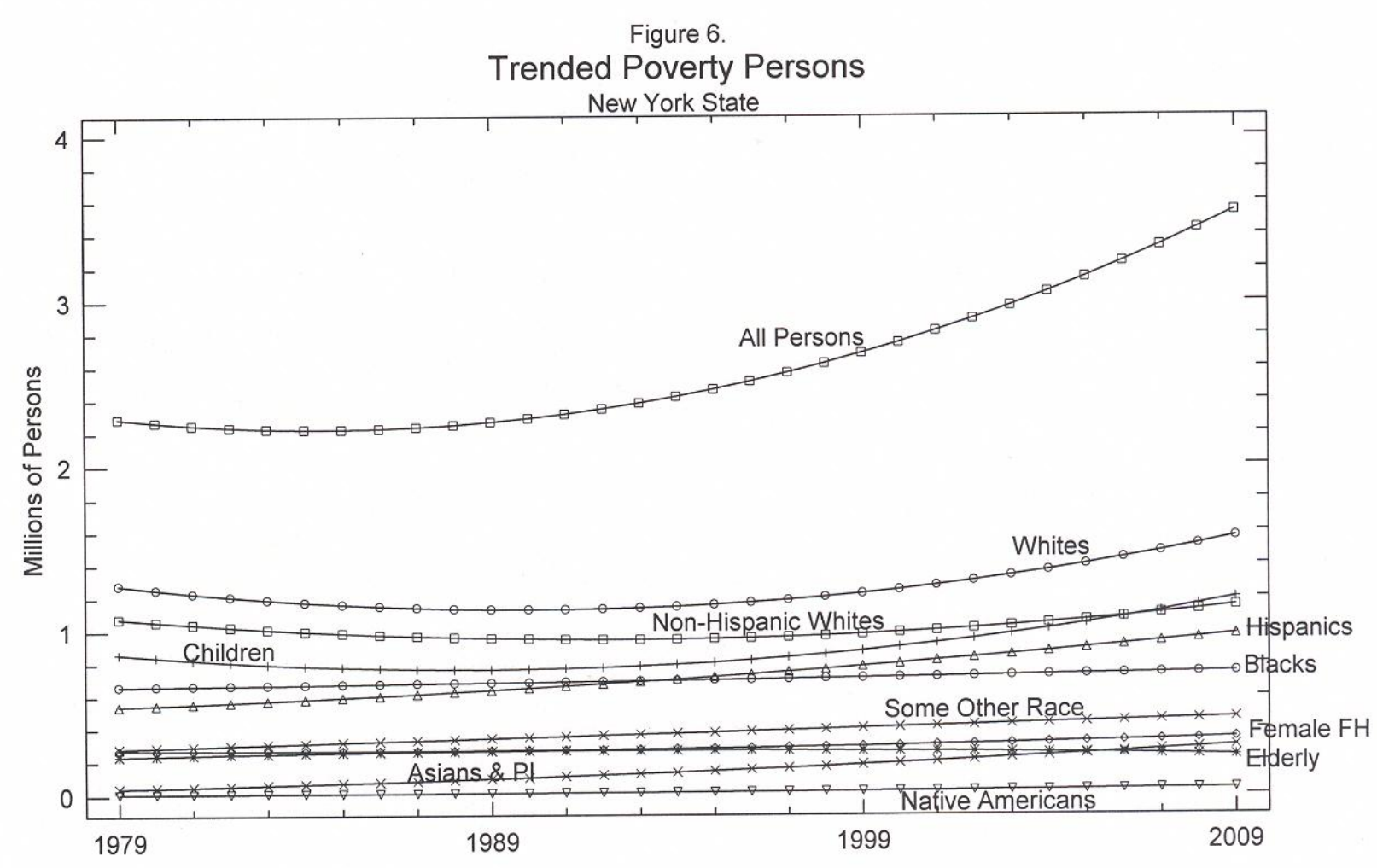

\section{SUMMARY \& CONCLUSIONS}

An important goal of this study has been to present a method of estimating and projecting annual poverty at the sub-national level, where the State of New York was chosen as the demonstration locale. Using benchmarks obtained from decennial censuses, poverty for various demographic groups was traced. After examining the past for each separate population segment, independent demographic projections were extrapolated a decade to year 2009. The evidence is revealing and hopefully of help to state legislators and administrators and to public and private social service organizations. This methodology can be easily replicated in other jurisdictional settings and levels.

The overall picture for New York State indicates that the incidence of poverty across all demographic groups is projected to rise over the next decade by $25 \%$ to over $18 \%$. A steep increase is also forecast for the number of impoverished residents within the State. By the end of the decade, the total number of poor persons is forecast to expand $31 \%$ to over 3.5 million. There will also be significant shifts among the demographic groups in their relative shares of State total poverty.

\section{REFERENCES}

1. Bureau of the Census, U.S. Department of Commerce, Washington, DC, http://www.census.gov/hhes/www/poverty.html.

2. Bureau of the Census, U.S. Department of Commerce, Statistical Abstract of the United States: 2002 (122nd edition), Washington, DC, 2002, Tables 22, 33, 34, 335, 420, 437, 684.

3. Mogull, Robert G., State Poverty: The Case of California, Journal of Social Service Research, forthcoming. 4. Mogull, Robert G., Metropolitan Poverty: The Case of New York City, The American Economist, forthcoming in 2005. 
5. Mogull, Robert G., Estimating \& Projecting State Poverty: The Case of Mississippi, Journal of Business and Economic Perspectives, XXIX (Fall/Winter 2003), 70-78.

6. Orshansky, Mollie, How Poverty is Measured, Monthly Labor Review, XCII (Feb. 1969), 37-41.

7. Orshansky, Mollie, Who's Who Among the Poor: A Demographic View of Poverty, Social Security Bulletin, XXVIII (July 1965), 3-32.

8. Orshansky, Mollie, Counting the Poor: Another Look at the Poverty Profile, Social Security Bulletin, XXVIII (Jan. 1965), 3-29. 